\title{
Empathy as a component of pedagogical optimism development
}

\author{
Zaliya Arskieva* \\ Chechen State University, Department of Pedagogy and Psychology, 364024 Grozny, \\ Russia
}

\begin{abstract}
This paper reflects the results of an empirical study on the development of empathy as a component of the formation and development of pedagogical optimism. An analysis of the ascertaining and formative experiment is carried out. The field of optimism research is considered as a positive factor in the success of the interaction in the educational process - the student, teacher.
\end{abstract}

Research in the field - optimism is a developing field. More optimism studies have been conducted over the past seven years than in the previous twenty. Considering the field of optimism studies, we are first struck by the overwhelming number of positive results associated with optimism, and then by the widespread tendency of people to optimism or positive bias in their worldview and self-esteem.

Psychologists classify the population as largely optimistic in their dimensions, that is, Segerstrom claims that about $80 \%$ of people are classified as optimistic, and Seligman claims that $60 \%$ of people are somewhat optimistic. Optimism has been noted as an important evolutionary part of survival [1, 2]. In his book Optimism: The Biology of Hope, the Tiger argued that this is one of our most defining and adaptive characteristics [3].

Studies have shown that optimism correlates with many positive life outcomes, including increased life expectancy, overall health, improved mental health, increased success in sports and work, higher recovery rates after heart surgery, and more effective coping strategies for dealing with facing difficulties.

To assess whether this study really proved that optimism is such a positive virtue, we need to understand the historical background that generated the first wave of optimism research.

The first wave of research focused on identifying optimism and creating measurement tools. This allowed researchers to find out what optimistic people can and will do. The resulting studies showed an almost amasingly positive picture in favor of the benefits of an optimistic outlook, whether it be disposition (Carver and Scheyer) or how we explain the events that happen to us (Seligman and Peterson). This, combined with the work of Shelley Taylor, who strongly argued in her book Positive Illusions that positive distortions of personal qualities, skill and appreciation of the future are widespread and in fact a sign of healthy, well-adapted people, ushered in optimism as desirable and positive hell. $[4,5]$

\footnotetext{
* Corresponding author: zaliya66@mail.ru
} 
They argued that optimism is linked and provides positive results, while pessimism is associated with more significant negative results. For example, in studies of young people, optimism was found to be associated with greater life satisfaction, while pessimism was found to be associated with more severe depressive symptoms $[4,6]$.

Carver and Scheyer see optimism as a disposition. They found that optimists report fewer physical symptoms, improved health habits, and improved survival strategies.

As a result of Seligman's famous study of "learned helplessness" in the 70s and 80s, i.e., the notion of "explanation style" was associated with the reaction of refusing the belief that everything you do is irrelevant. It was developed on the bases of analysis and models of how people explained the events that happened to them.

Seligman developed this optimism analysis with several other colleagues. He is the author of The Studied Optimism, and then The Optimistic Child, to emphasize the connection between optimism and pessimism and some styles of explanatory style.

Seligman developed attributive retraining to help people "learn optimism." According to this point of view, those who explain bad events as internal (caused by them), persistent (will happen further) and global (will occur in other areas of life) reasons are called pessimistic, and those who prefer external, unstable and specific reasons are described how optimistic [7].

The theory was developed in the context of acquired helplessness, and therefore it can rely too heavily on the notion that lack of pessimism creates optimism. The use of "learned optimism" aims to reduce helplessness / depression using cognitive therapy models developed by Beck and Ellis $[8,9]$.

These cognitive-behavioral methods may not really teach people "optimism," but on the contrary may simply reduce pessimism. Peterson, himself a proponent of explanatory style, warns that ("Studies of optimism (that is, an optimistic explanatory style) will not be so significant if they are closely related to the theory of helplessness." [10, p.122].

With so many positive correlates, there were many questions related to research results that challenged the notion of the optimism benefits.

"Pessimism is an ingrained habit of the mind that has radical and catastrophic consequences: depressed mood, lagging, failure and even poor physical health," Seligman states in his book, An Optimistic Child [11].

They characterize optimism as cheerfulness, faith in the future, success, and the desire to see good. Despite the fact that children are optimistic about the world, they are disappointed to encounter difficulties and, therefore, the teacher should be able to help. So, as optimism is like a magic colored glass through which the outside world seems more miraculous [12].

Sometimes parents and teachers set high expectations for children.

Accordingly, it is difficult to raise an optimistic mood in the child, which will be accompanied with joyful perception and positive in case of failure.

Therefore, parents and teachers need to take into account the degree of activity and ability of the child since there are children with a high degree of activity who are ignited by the idea and included in the activity, but there are those who tend to retreat, at the slightest barrier; children who find it difficult to adapt to new situations, they need time to get used to the new environment; there are children who are usually in a bad mood ("boring"). They are very vulnerable and need attention and sensitivity from adults.

Taking into account that pedagogical optimism is based on feelings of joy arising in creative work and is able to reveal the natural talent of the child, it forms a moral and aesthetic ideal, a teacher should have the ability to unleash the child's creative potential, support the desire for self-expression with a kind word and a sensitive attitude. This approach of the teacher contributes to the moral and physical health of the child. In the 
words of Sukhomlinsky V.A. "Optimism, faith in a person is an inexhaustible source of creative energy, nervous energy, the health of a teacher and student" [12, p.179]

Optimism eliminates hostility, anger and suspicion in the relationship between teacher and student, creates a lively, joyful atmosphere of communication and understanding, and causes a feeling of happiness.

We consider pedagogical optimism in the unity of three components: a sense of humor, communicativeness and empathy.

The purpose of our study was the features of the development of pedagogical optimism in future teachers by means of developing cognitive interest. During the experiment, a model for the development of pedagogical optimism was developed on the basis of the formation of three main components: a sense of humor, communication and empathy.

In this article we will consider the level of development of one of these components as empathy.

The empathy of the ability to understand and feel the inner world of their wards is one of the factors for the success of the interaction during the educational process. Thanks to this approach, teachers are able to implement better a differentiated approach to students, be more attentive to children's feelings, more likely to engage in dialogue with students and use their thoughts in the lesson.

The initial step in our study was the diagnosis of this component development level among bachelors as a necessary type of communication between an optimistic teacher who believes and gives hope for success in his students. We identified the level of this component development based on the method of rapid diagnosis of empathy according to I.M. Yusupov; the results of the primary diagnosis are shown in table 1.

Table 1. Level of formation structural components of empathy in bachelors EG and KG at the initial stage from $100 \%$.

\begin{tabular}{|l|c|c|}
\hline \multicolumn{1}{|c|}{ Levels } & \multicolumn{2}{|c|}{ The structural component of empathy } \\
\hline High level & Experimental group & Control group \\
\hline Average level & 47 & 44 \\
\hline Low level & 24 & 30 \\
\hline
\end{tabular}

The level of this component formation in the two experimental groups shows no significant difference, so the high level in the experimental group was $47 \%$, but in the control group $44 \%$, which shows a difference of $3 \%$. The average level has a difference of $6 \%$, the low in both groups has $3 \%$ more and less. The results indicate an insignificant level of development of empathy in two experimental groups, which leads us to the development of this component by conducting a formative experiment using a model of the development of structural components.

The results of the formative experiment are shown in tables 2 .

Tables 2. Level of formation structural component like empathy in bachelors EG and KG at the final stage from $100 \%$.

\begin{tabular}{|l|c|c|}
\hline \multicolumn{1}{|c|}{ Levels } & \multicolumn{2}{|c|}{ The structural component of empathy } \\
\hline & Experimental group & Control group \\
\hline High level & 56 & 48 \\
\hline Average level & 38 & 32 \\
\hline Low level & 9 & 14 \\
\hline
\end{tabular}

The result of the formative experiment confirms the purpose and hypothesis of our study. The effectiveness of the development model of structural components in this case of 
empathy, as one of the components of pedagogical optimism, is confirmed. Over the period of this experiment, the performance of the expert group increased by $9 \%$, and in the control group this figure is not significant, which is $-4 \%$.

\section{References}

1. M.E. Seligman, Learned Optimism (Simon \& Schuster, New York, 1990)

2. S.C. Segerstrom, Breaking Murphy's Law (The Guildford Press, New York, 2006)

3. L Tiger, Optimism: the biology of hope (Simon \& Schuster, New York, 1979)

4. S.E. Taylor, Positive Illusions: creative self-deception and the healthy mind (Basic Books, New York, 1989)

5. M.F. Scheier, C.S. Carver, Cognitive Therapy and Research, 16, 201-228 (1992)

6. E.C. Chang, A. Maydeu-Olivares, T.J. D'Zurilla, Personality and Individual Differences, 23, pp. 433-440 (1997)

7. E.C. Chang, Journal of Personality and Social Psychology, 74, 1109-1120 (1998)

8. A.T Beck, Depression: Clinical, experimental and theoretical aspects (Hoeber, New York, 1967)

9. A. Ellis, R.A. Harper, A new guide to rational living (Wilshire Books, North Hollywood, 1975)

10. C. Peterson, A Primer In Positive Psychology (Oxford University Press, New York, 2006)

11. M.E.P. Seligman, Learned Optimism (Simon \& Schuster, New York, 1990)

12. V.A Sukhomlinsky, I will give my heart to children (Conceptual Publishing House, 2016)

13. Z.A. Arskieva, The European Proceedings of Social \& Behavioural Sciences, LVIII, 135-141 (2019) 